\title{
EUROPEAN DRIVING RANGE - INNOVATIVE LANDSCAPES FOR A TANGIBLE, NON- HIERARCHICAL LEARNING SPACE WITHIN A MATERIAL AND IMMATERIAL TOGETHERNESS
}

\author{
Marina-Elena WACHS ${ }^{1}$ and Ashley HALL ${ }^{2}$ \\ ${ }^{1}$ Hochschule Niederrhein, Faculty of Textile and Clothing Technology, Germany \\ ${ }^{2}$ Royal College of Art, London, UK
}

\begin{abstract}
The $21^{\text {st }}$ century global scale challenges facing design include sustainability, migration, food, water and data security and terrorism amongst others. These challenges have left $20^{\text {th }}$ century design approaches lagging behind, while we also now recognise that the 'western' design model is limited. As geopolitical changes accelerate in Europe, new opportunities and challenges are emerging in collaborating for a profitable "togetherness". The demand for high value designed products created across the future European landscape will require new educational talents working seamlessly across integrated analogue and digital platforms while responding to evolving cultural needs emerging through new consumer behaviours. With the help of a differentiated design landscape we are developing the capabilities to meet the future needs of innovation and design engineering opportunities in the $4^{\text {th }}$ industrial revolution including: new standards in the digitalised learning landscape, new design methods for cross cultural creativity and understanding, higher levels of integration between qualitative and quantitative approaches in design-engineering, redefining borders of design collaboration, engineering creativity, knowledge sharing in non-hierarchical cross-cultural learning and differentiated analogue and digital education skill bases in a connected European learning landscape for increasing creative diversity. The 'European Designer Driving Range' explores a concept that gives us the possibility to reflect on the needs for tomorrow from a pan-European perspective. We aim to identify the key drivers for a collaborative European non-hierarchical learning landscape and explore how these could be engaged through a future platform.
\end{abstract}

Keywords: Creative process, European design education, immateriality, future education strategy, non-hierarchical, cross-cultural design space

\section{INTRODUCTION}

Much has been written on collaboration and cross-cultural exchanges in product design and design engineering, however comparisons at a European scale initiated to discuss current and projected future European design issues are rarer. The 'local' and 'global' are common geographical spaces for design discussions whereas the continental scale is less of a focus. Our discussion begins with a comparison between Germany and the UK exploring similarities and differences between design engineering provision at national levels to draw out a conversation that focusses on the range of drivers for future development of Europe wide design engineering education.

\section{COMPARING NATIONAL DESIGN ENGINEERING EDUCATION MODELS}

\subsection{Germany}

In line with the German Bauhaus heritage that focussed on the correlation between art, technique, and the affordance of social participation from every citizen, design schools like Hfg Ulm and other "Werkkunstschulen" shaped German industrial design education. The parallel awakening of governance, responsibility and the attitude of the Geschwister Scholl Foundation after WWII founded the German Design Council (Rat für Formgebung) in 1953 [1]. The aim was to communicate the best 
form and best product language (Steffen) of industrial production which promoted the serious production of ideal during the German Wirtschaftswunder. The mark "Made in Germany" was based on high industry quality and standards in materials and manufacturing techniques generating the beginnings of long running economic profitability. Only with designers like Dieter Rams and Braun did the German Design heritage in product design that is known today begin. In other words, German Design is based at the one hand on industrial design (partnering with design engineering) supported by a history of industrial design education based on form and function related to Bauhaus with artists like Itten, Kandinsky, Albers and Max Bill. On the other hand, industrial design is also based on craftsmanship at the laboratories of the Werkkunstschulen, in combination with a new consciousness for reflecting design (e.g. University of Arts Braunschweig) with a long tradition of caring about the historical benefits of cultural behaviour. Related to the attention to the semantic meaning of products (Barthes, Haug, et al) in the 1960s a new driving range of theorists pushed product related messages. The 1980's developed a new spirit of design thinking via historian Bürdek, the scientist of design van den Boom [2] and Krippendorf connected different educational disciplines to unite the design language of products, services and concepts. Besides the universities of applied science, which followed the great pressure of industrial needs, universities developed a broader mindset with new terms like the model of "design thinking" that today bears similarity to the original "Thinking Design" of Rittel [3].

The focus went from form - to function - to product language in German design theoretical reflection with the interdisciplinary connectivity between French philosophers like Barthes, Foucault, Derrida and architectural theorists including Lampugnani and Zumthor. This allowed the material behaviour and cultural behaviour about the "things" on three levels to awake. "Things" have to be interpreted by the meaning regarding a 3D object, by the written object (described by words) and importantly today via images. Today we appreciate products as things and objects thanks to Hans Peter Hahn in different relationships; relating to the psychological, the sociological, the historical and cultural perspectives. They generate a holistic view of the meaning of design engineered products and processes, mirroring evolution in time. Historical drivers like Walter Gropius and students at the Bauhaus 100 years ago, Max Bill and his guest lectures including Gui Bonsiepe and students at the Hfg Ulm, and developments during the 1960's gender and political revolution illuminated a new view of design education. Only with the new consciousness and support by powerful institutions and ambassadors (Geschwister Scholl Foundation, Rat für Formgebung, Deutsche Werkbund, to mention only a few) could society recover a necessary role to design things with new technological possibilities and new design methods.

The next great step in design (-reflection) appeared in 1980s, when the new business field of design management became influenced by female concerns through Brigitte Wolff and product language by the Offenbacher Manifesto that was resumed by Dagmar Steffens [4]. Everything is language! This development led to the first doctoral programmes at the end of 1980s in German Universities of Arts (e.g. HBK Braunschweig) moving from hard industrial technique to higher cultural value. Again, with new perspectives. This time with the help of different anthropological approaches for evaluating in $\mathrm{EACH}$ discipline the next industrial, social and economic revolutionary steps influencing the curriculum of universities in design engineering.

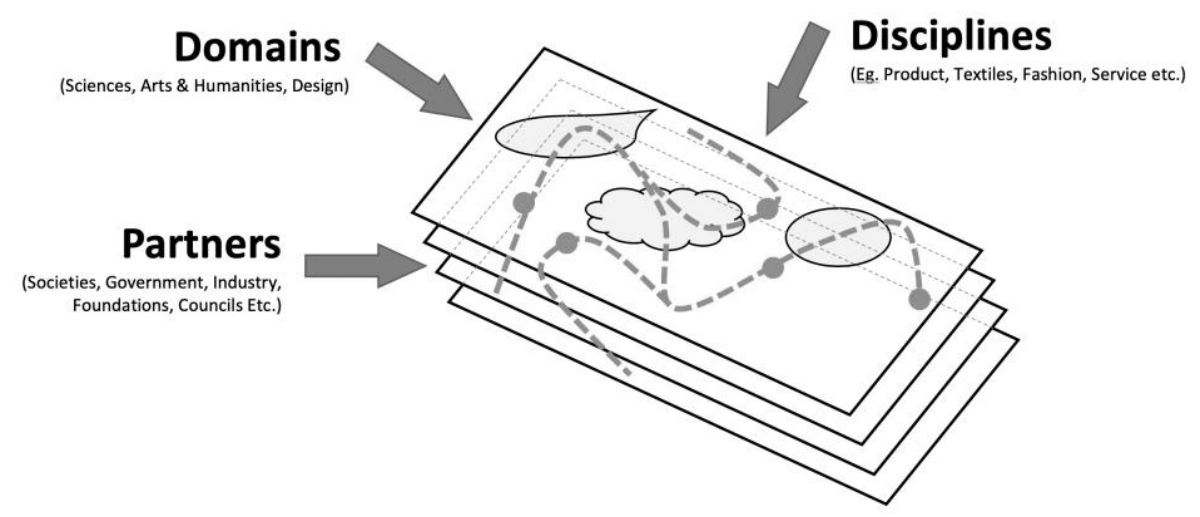

Figure 1. Non-hierarchical learning landscape for design engineers including domains and partners 
The appearance of innovative formats influenced by the Bologna process led to new university study programmes focused on integrating the European complexity in educational landscapes. However, with real time comparability from digital information networking, a better cultural understanding is needed to work together in digitally connected working spaces wherever we are. Everything is language, but also driven by a little group of reflected persons, of thinkers and makers (Figure 1). Design engineering history in Germany is based on the one hand on a high quality of technical knowhow and on the other hand by very engaged passionate people like the shoe maker Dassler who build up the Adidas. The great dynasties of family led businesses from the lower Rhein region in Germany who built up the success of steel in Germany supported the 'Made in Germany' profile during the $20^{\text {th }}$ century [5].

Today a beneficial addition of representing institutions like the German DGTF (The German Society for Design Theory and Research, since 2003) and the DHS (Design History Society, since 1977), and others mentioned above are supporting an essential view of design. At the same time the growing cross-cultural publication of articles and books of a more theoretically engaged design community is pointing towards a good communicating across the European design community.

Reflecting on the common themes for future learning landscapes in design engineering in Europe we realise the first industrial revolution made great engineering quality possible both in the UK and Germany. Every time social reflection on cultural and material behaviour occurred, craftsmanship and engineering education brought the next step with the help of passionate people and by the support of councils and organisation. However, we don't yet know why using the terms 'design' and 'design engineering', are perceived differently across cultures. While Germany is cultivating the separation between design and engineering, it is clear that engineering originally related to mechanical engineering and design originally related to creative industries. This gap will have enormous influence for design methods within the $4^{\text {th }}$ industrial revolution and future educational landscapes.

\subsection{United Kingdom}

Although the industrial revolution spawned the introduction of art colleges and government schools of design in the UK from the 1830's, the focus was firmly on design 'serving' industrial needs. Design was very much at the end of the process and a latterly addition to humanising machines and engineered technology packages. Robin Darwin [6] had proposed bridging the domains of design and engineering as early as 1945 following his role as secretary to the training committee for the Council for Industrial Design (CoID). However, it took until 1980 for the first industrial design engineering postgraduate course to be set up between the Royal College of Art and Imperial College [7][8]. Ewing's PhD described the evolution of the design engineering curriculum and pedagogic debate that finally agreed on a project-based format bridging technical excellence and creativity [7].

Contemporary developments have seen a move in some engineering design programmes towards an innovation focus where design and engineering have dissolved into a landscape of fluid methods that support both disruptive and experimental design led innovations. While this has brought new opportunities, issues remain and some new ones are emerging for design education. Increasing technological complexity can challenge the traditional engineering-based teaching of technology principles. For example, technologies that can be 'known' verse black box technologies which need different epistemological approaches based on comparisons of inputs and outputs, and knowledge of restraints. Artificial intelligence is one such field where it is widely recognised that its 'black box' nature is challenging traditional forms of technology development and exposing new types of risks [9]. A welcome development has been the increase in cultural diversity and disciplinary crossover from other fields into engineering design, especially at postgraduate level. This has brought with it a greater variety of creative design methods, new approaches and insights alongside applied digital and analogue making and craft skills enriching the area. The challenges that have arisen require a shift of level from delivering education from undergraduate to postgraduate within the same discipline, to a focus on including wider disciplinary perspectives and a certain amount of foundational principles to bring more diverse student cohorts quickly up to speed. This has brought into question the value of traditional design skills and their ongoing relevance verses cross disciplinary design led innovation skills. When some students are graduating from postgraduate engineering design degrees without an ability to draw, yet express themselves creatively though code, this challenges the longstanding tangible foundations of design education. As technologies like the aforementioned AI alongside biotechnology and nanotechnology become more intangible as a result of their material scale of 
operation, these technologies challenge long held traditional tangible models of 'skills sets' and more importantly the idea of thinking through making [10]. Immateriality and intangibility alongside new languages for creativity challenge structures, assumptions, teaching models and the perspective of educators. Cultural behaviour in design engineering has also emerged as an issue both internally within the discipline from a point of view of its global fitness for purpose, compatibility with other philosophies [11] and also its tendency for colonisation [12] of creative methods potentially limiting global design variety [13]. When considering UK design education, one could argue that the challenge is that it sees its practices primarily operating in a local-global scale that largely ignores that of the European.

In our national comparisons we aim to explore these similarities and differences to develop a discussion for what can drive the range of future requirements for future European engineering design education. Using different design languages in different material and immaterial learning landscapes in the future needs a common understanding of historical based designing behaviours linking to future European design engineering challenges.

\section{CASE STUdies - INNOVATIVE CREATIVE PROJECT SPACES}

A number of experimental educational projects and initiatives were developed by one of the authors in the UK in order to tackle some of the perceived issues in teams of cross-cultural multi-disciplinary design engineering postgraduate students. These concerned issues in the areas of developing communications in multi-disciplinary groups, the problem of resistance to failure in design experimentation and developing competence in tangible aesthetic design language. In interdisciplinarity the assumption made in the literature is that we should strive for clear communications and that any errors in communicating ideas can reduce creativity thereby producing weaker design solutions [14].

However, research on missing miscommunications has proved that miscommunications, especially at the early creative stage of interdisciplinary cross-cultural design project can lead to new creative capital and bring forward new and impactful innovation concepts [14]. The researchers used a process of c-sketching and analysed group emotional journeys that were compared to creative outputs. These were then cross referenced across the entire sample (40+) in order to discover that ambiguous misunderstanding leads to differences, many of which were not intended by the initiators but later on inspired unintended innovation routes.

Failure is frequently avoided by design students and it seems that this is especially the case with those from technical and scientific backgrounds. Often this is for good reason for example in reducing risks in critical structures. In design led innovation and especially in design engineering failure is a key ingredient on the road to success. 'I have not failed, I found 10,000 ways that won't work' stated Thomas Edison and the classic Becket quote 'Ever tried. Ever failed. No matter. Try again. Fail again. Fail better.' The Elastic Octopus module [15] was developed to challenge students to fail. They would succeed in direct relation to their ability to fail after being challenged in a series of unsolvable experimental challenges. The groups were then asked to map their experimental failures. The groups completed a significant number of 20-30 experiments each within a two-week period. When the designs were reviewed it became clear that some groups had in fact succeeded, yet described their project as a failure by invoking a kind of cognitive dissonance [16]. Ultimately the key insight came from one student interviewed after the module who claimed that the project improved her creative resilience to failures and that she was much happier to take on future design challenges when the end result was unclear.

The third pedagogic experiment was driven by noting the lack of tangible aesthetic design skills needed for discussing design innovations. The ubiquity of screen based creative tools and the high level 'finished' quality of digital content has had an impact on tangible form creation by students. We developed a series of tangible aesthetics workshops [17] which sought to improve skills for developing analogue analysis for differentiating objective and subjective qualities leading to identifying affordances and signifiers. Although we found that differentiating between objective and subjective features was more difficult for students that first envisaged, they were able to begin appreciating the value of developing their own competence in form language. All three projects taken together indicate that although there are many advantages and positive outcomes for teaching cross cultural interdisciplinary groups that there are also new challenges that need resolving. 
The German point of view characterises the innovative learning landscapes of the last ten years from interdisciplinary projects connecting different study programmes (design engineering, textile and clothing management, textile technology, product development, etc.) from different levels including BA and MA students. The experiences of innovative didactic impact in the study programmes not only profited from an interdisciplinary outlook and learning benefits through participation, but also a nonhierarchical understanding in communicating ideas with different media [18]. The aim is clearly effective in researching on the subject of smart and sustainable solutions, communicating and mediating in a reflective area through multiple perspectives in a multidimensional concept of design thinking. The next step after generating a learning landscape of reflecting interdisciplinary and nonhierarchical structures at the student level within the university educational space is first create a nonhierarchical designing and thinking maker space of students, teachers and experts from outside. Secondly to initiate an open and connected European cross-cultural analogue and digital communication field.

The 2019 cross-cultural Textilepop multidisciplinary workshops held in Germany on the common subject of smart sustainable solutions brought a lot of experiences together via a new designer driving range in a tangible non-hierarchical learning landscape outside the box of the university. This first European designed landscape supported by designers and educators from the UK, Sweden, Switzerland and Germany underlines the need to support and enhance a cross European landscape.

\section{DEFINING NEEDS FOR FUTURE DESIGN LANDSCAPE STRATEGIES}

Defining the needs of a future European design landscape in many ways bucks the trends of globalisation and localisation by considering a middle scale. The question of what constitutes 'European' from a design perspective can be seen from geographical, political, cultural, historical and economic perspectives. Recent global geo-political developments, shifts in power relations, trade imbalances and a move towards digital conflict have reframed the need to understand valuable design connections and alliances operate at a European level.

In order to foster a better-connected European design engineering practice, we need to improve the digital uUniversity landscape and support role models of new and emerging forms of innovation in design engineering. It is essential to maintain the tangible analogue skills in drawing and sketching to win the digital, yet we need to make spaces in our curriculums for this. Drawing is the basis of discussion in many design sectors as much as coding is in AI and other technical fields where design has yet to fully engage. The benefit could involve connecting undergraduates and research students in independent working spaces across Europe with the help of improved digital connection tools. The aim is to construct a European strength for transmitting and discussing design issues at the same time as generating together our new future European smart design solutions.

Do we need a Europe-wide common understanding of designing and design engineering which looks at the new ethical and methods challenges of working with artificial intelligence, robotics and the generative automation of engineering practices? Smart micro and macro factories need thinkers and talents from all educational levels and researchers working together at a connected European level. Klaus Schwab in 2016 underlined the beneficial factors and economical power of human capital in that we have to invest in a stronger togetherness in our shifted geopolitical circumstances.

\section{A NON-HIERARCHICAL CROSS-CULTURAL RANGE OF DESIGNERS}

Projecting future design issues across Europe requires a re-appraisal of our design engineering landscapes. No longer do we believe there will be any universal answers in design and the global decolonisation of design has begun. While there is ample debate for national design policies and the effects of localisation and globalisation, less attention is paid to European level discussions on the barriers, challenges and opportunities of future design engineering education. Although European initiatives like Horizon 2020 and Erasmus have been major contributors to knowledge gathering and improving the competitiveness of the EU economy, there has been relatively little focus on the future strategic needs of a specifically European design future and the key drivers that support the needs and issues to overcome. Drawing together conclusions from our discussion on the future drivers for success in training the new generation of European engineering designers several issues have emerged: the cultural understanding of different cultural habits and engineering histories, tensions between traditional 'classic' industrial design teaching methods and the needs of new emerging design 
disciplines, intangible technologies and designing beyond discipline, the need to face mutual interaction and reflection. In addition, the financial support for design, engineering and management by the European parliament's needs reviewing with a key focus on the drivers for a holistic panEuropean view of improving design engineering spaces for education.

The disparity between the national integration of design and engineering disciplines across Europe remains a barrier and the need to develop new continental cultural models of design that recognise Europe as a powerful and essential design culture in its own right remains. The opportunities for a new future European design landscape include on the one hand recognising the need to develop a stronger concept of European culture in terms of design methods in respecting and embracing cultural diversity. Our comparable views of design education history in the UK and Germany leads us to two important questions: Could the concept of a 'European' designer driving range bridge the gap between globalisation and localisation at a European scale? Could this offer a new perspective to see different relationships between traditional analogue and contemporary digital future skillsets within a more collaborative digital environment for European designers and students to create new partnerships? The benefits of the digitalisation in connected study programmes for cultural understanding, optimised processes and sustainability cannot be ignored. Our common reflection on European design history and industry related to the development of educational programmes leads us to sketch a European driving range as an innovative landscape for a tangible, non-hierarchical learning platform with benefits for a material-immaterial design togetherness. We propose focussing on a fundamental design engineering shift in education programmes for Europe's future.

\section{REFERENCES}

[1] Bürdek B.E. (2005), Design history, theory and practise on product design, (Birkhäuser, Basel).

[2] Van den Boom H. (2011), Das Designprinzip, Warum wir in der Ära des Designs leben, (Kassel University press, Kassel).

[3] Rittel H.W. edited by Reuter W.D. and Jonas W. (2013), Thinking Design - Transdisziplinäre Konzepte für Planer und Entwerfer, (1992), (BIRD Birkhäuser, Basel).

[4] Steffen, D. (2000), Design als Produktsprache - Der "Offenbacher Ansatz" in Theorie und Praxis, (Verlag form theorie, Frankfurt am Main).

[5] Wachs M.E. (2008), Material Mind - Neue Materialien in Design, Kunst und Architektur, (Dr. Kovac, Hamburg).

[6] Gooden H. (2015), Robin Darwin: Visionary Educator and Painter, Unicorn Press, London.

[7] Ewing P. (1988), The Teaching of Industrial Design Engineering, Doctoral Thesis, Department of Industrial Design, Royal College of Art.

[8] Hall A. and Childs P. (2009), Innovation design engineering: Non-linear progressive education for diverse intakes, EPDE, September 10-11, University of Brighton, UK.

[9] Devlin H. (2017), Retrieved 10th February 2019 https://www.theguardian.com/technology/2017/apr/13/ai-programmes-exhibit-racist-and-sexistbiases-research-reveals

[10] Sennett R. (2008), The Craftsman, New Haven: Yale University Press.

[11] Brezing A., Childs P.R.N. et al. (2011), Approaches to a Cross-Cultural Engineering Design Theory. E\&PDE, London.

[12] Diethelm J. (2006), Decolonising Design thinking, The Journal of Design, Economics, and Innovation, Vol. 2, No. 2.

[13] Hall A. (2017), Is Globalised Design Education Killing Design Variety? EPDE, Oslo, Norway.

[14] Torrisi S. and Hall A. (2013), Missing Miscommunications in Interdisciplinary Design Practice, EPDE, Dublin Institute of Technology, Ireland.

[15] Hall A., Bahk Y., Gordon L. and Wright J. (2016), The Elastic Octopus: A Catalogue of Failures for Disrupting Design Education, EPDE, Aalborg, Denmark.

[16] Festinger L. (1957). A theory of cognitive dissonace. Evanston, USA: IL: Row Peterson.

[17] Hall A., Ferrarello L. and Li W. (2018), Introducing tangible aesthetics: Contrasting the introduction of aesthetic analysis tools for product designers and interdisciplinary design researchers, EPDE, London, UK.

[18] Wachs M.E. (2018), Driver for sustainable (industrial) design culture - the >design shift<, EPDE, London, pp. 394-399. 